\title{
Potencial de produção de biogás a partir da Co-digestão de dejetos da suinocultura e bovinocultura
}

Os dejetos produzidos pela criação de animais em confinamento, quando não tratados adequadamente, podem causar impactos ambientais A digestão anaeróbia é uma tecnologia para o tratamento destes efluentes, que converte matéria orgânica em biogás, um gás combustível que pode ser aproveitado energeticamente. A produção de biogás está relacionada com as características da biomassa e com a quantidade de carga orgânica a ser digerida no sistema. Pode-se aumentar a concentração orgânica a partir da co-digestão anaeróbia, mesclando diferentes tipos de biomassa em um mesmo sistema de biodigestão. Este estudo constatou que a co-digestão dos dejetos da suinocultura e da bovinocultura potencializa a produção do biogás e a concentração de metano, em relação a digestão isolada destes substratos. A co-digestão da amostra composta por $75 \%$ de dejetos da suinocultura e $25 \%$ da bovinocultura, apresentou o maior potencial de produção do biogás e presença de metano, com 551 LN biogás.kg SV-1 e 445 LN metano.kg SV-1. A digestão dos dejetos da bovinocultura apresentou maior produção de biogás (490 LN biogás kgSV-1) comparada a digestão dos dejetos da suinocultura (422 LN biogás kgSV-1).

Palavras-chave: Biogás; Biomassa; Co-digestão Anaeróbia.

\section{Biogas production potential from Anaerobic digestion waste of the swine and cattle}

\begin{abstract}
The waste produced by the creation of animal in confinement, when not properly treated, can cause environmental impacts. Anaerobic digestion is a technology for the treatment of these effluents, that converts organic matter into biogas, a fuel gas that can be converted into energy. Biogas production is related with the biomass characteristics and quantity of organic load to be digested by the system. One can increase the concentration of organic from the anaerobic co-digestion, mixing different types of biomass in the same system of digestion. This study found that the co-digestion of manure from swine and cattle enhances the production of biogas and the concentration of methane, in relation to the isolated digestion of these substrates. The co-digestion of the sample composed of $75 \%$ manure from swine and $25 \%$ manure from cattle, showed the highest biogas production potential and presence of methane in the biogas, with 551 LN biogás.kg SV-1 e 445 LN metano.kg SV-1. The digestion of cattle manure showed highest production of biogas (490 LN biogás kgSV-1) compared to the digestion of manure from swine (422 LN biogás kgSV-1).
\end{abstract}

Keywords: Biogás; Biomassa; Co-digestão Anaeróbia.

Topic: Sistemas de Energia Sustentável

Reviewed anonymously in the process of blind peer.

Caroliny Matinc

Universidade do Vale do Taquari, Brasil http://lattes.cnpq.br/1140817732648349 caroliny.matinc@gmail.com

Jaqueline Fernandes Tonetto

Universidade Federal do Rio Grande do Sul, Brasil

http://lattes.cnpq.br/9770056656475650

jaquetonetto@gmail.com

Camila Hasan

Universidade do Vale do Taquari, Brasil

http://lattes.cnpq.br/1967237941851023

chasan@univates.br

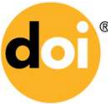

DOI: 10.6008/SPC2179-6858.2017.004.0013
Received: 15/07/2017

Approved: 15/10/2017

\author{
Odorico Konrad \\ Montanuniversität Leoben, Áustria \\ http://lattes.cnpq.br/9946679953072196 \\ okonrad@univates.br
}

Referencing this:

MATINC, C.; TONETTO, J. F.; HASAN, C.; KONRAD, O.. Potencial de produção de biogás a partir da Co-digestão de dejetos da suinocultura e bovinocultura. Revista Ibero-Americana de Ciências Ambientais, v.8, n.4, p.154-161, 2017. DOI: http://doi.org/10.6008/SPC2179$\underline{6858.2017 .004 .0013}$ 


\section{INTRODUÇÃO}

A crescente preocupação com as mudanças climáticas, o uso racional dos recursos naturais e a segurança energética fez com que vários países desenvolvessem tecnologias para a utilização de fontes renováveis de energia, visando então diminuir impactos ambientais relacionados a tais causas. Segundo o Balanço Energético Nacional (2015), em 2014, o Brasil gerou 39,4\% de energia utilizando fontes renováveis, um dos maiores índices do mundo. Neste índice, as fontes de energia se dividem em biomassa da cana 15,7\%, hidráulica $11,5 \%$, lenha e carvão vegetal $8,1 \%$ e outras renováveis $4,1 \%$.

Goldemberg et al. (2008) conceitua as energias renováveis como aquelas que em condições naturais se restituem, por um curto período de tempo após captados, seus recursos como matéria-prima para geração e ainda consideram fontes destas a energia solar, a geotermal, a eólica, a hidráulica e a biomassa. A biomassa é considerada como toda matéria orgânica que possa ser utilizada como fonte de energia. Em escala mundial, é crescente o uso de biomassa para geração de energia elétrica, térmica e combustível (DRESSLER et al., 2012). O Brasil apresenta alto potencial energético proveniente da biomassa, decorrente da sua grande atividade agropecuária.

A biomassa pode ser convertida em biogás por meio da digestão anaeróbia, principalmente aquelas advindas dos resíduos orgânicos da agricultura, da pecuária e da indústria (BACENETTI et al., 2014). Segundo Hublin et al. (2012), o principal diferencial do tratamento anaeróbio é justamente o fato dos resíduos orgânicos serem fonte importante para a geração de energias renováveis, tanto pela sua alta produtividade nos setores pecuaristas, quanto também nos resíduos industriais e urbanos. Sendo assim, transforma-se um passivo degradante em uma solução ambientalmente adequada, em uma fonte energética que agrega renda pela utilização do biogás gerado pelo tratamento anaeróbio.

O biogás é uma fonte de energia renovável com alto teor de gás metano semelhante ao gás natural, podendo ser utilizado na geração de energia elétrica, térmica e veicular (WEILAND, 2009). O interesse pelo biogás como fonte de bioenergia é crescente, e sua exploração diminui o consumo à base de óleo fóssil (COMPARETTI et al., 2012). Desta forma, a atual valorização do biogás como um produto do meio rural despertou a necessidade de reconhecimento de formas para otimização da produção de biogás nos sistemas de digestão anaeróbia. Neste sentido, uma maneira de aumentar a produção de biogás é elevar o teor de sólidos voláteis na composição da biomassa, podendo ser realizado a partir da co-digestão de dois ou mais tipos de biomassas.

Garfí et al. (2011) afirma que a co-digestão anaeróbia de uma mistura dos substratos pode superar a digestão anaeróbia de somente um único substrato, pois proporciona uma composição de biomassa de maior qualidade, aumentando a comunidade de microrganismos e otimizando o processo anaeróbio. Neste sentido, o processo de co-digestão é uma alternativa, comprovada para aumentar significativamente a produção de biogás, entretanto devem ser utilizados biodigestores adequados para as biomassas a serem fermentadas (JENSEN et al., 2014).

Konrad et al., (2012) identificou o aumento de 206,07\% do potencial de produção de biogás, a partir da co-digestão anaeróbia de dejetos de bovinos com glicerina, como também o acréscimo de 157,36\% no 
potencial de produção do metano. Deste modo, neste trabalho analisou-se a produção de biogás a partir da co-digestão de dejetos da suinocultura e bovinocultura e identificou-se a melhor proporção destes, visando otimização na produção de biogás da Granja Colombari, localizada no município de São Miguel do Iguaçu/ PR.

\section{MATERIAIS E MÉTODOS}

A Granja Colombari foi a primeira micro central termoelétrica a biogás do Brasil, com a venda de energia elétrica no sistema de Geração Distribuída, disponibilizando no ano de 2012 uma média de 29MWh por mês de energia elétrica, para a venda à companhia Paranaense de Energia Elétrica (COPEL). O local do estudo situa-se na coordenada UTM X em metros 779037.734813 e Y em metros 7177094.9012, situada na linha Marfim, no município de São Miguel do Iguaçu na região Oeste do Paraná. A propriedade possui uma área de 250 hectares, sendo que 50 hectares são direcionados a criação de suinocultura e bovinocultura.

As análises dos parâmetros físico-químicos e determinação do potencial de produção do biogás, foram realizadas para os substratos da suinocultura, bovinocultura e a co-digestão destes substratos. Os ensaios laboratoriais foram realizados com nove amostras, em diferentes proporções dos dejetos da suinocultura e bovinocultura, conforme a tabela 1.

Tabela 1: Proporções de biomassa residual de dejetos de suinocultura e bovinocultura em cada amostra.

\begin{tabular}{|c|c|c|}
\hline Amostras & Dejetos suinocultura & Dejetos bovinocultura \\
\hline 1 & $100 \%$ & $0 \%$ \\
\hline 2 & $0 \%$ & $100 \%$ \\
\hline 3 & $90 \%$ & $10 \%$ \\
\hline 4 & $85 \%$ & $15 \%$ \\
\hline 5 & $75 \%$ & $25 \%$ \\
\hline 6 & $70 \%$ & $30 \%$ \\
\hline 7 & $65 \%$ & $35 \%$ \\
\hline 8 & $60 \%$ & $40 \%$ \\
\hline 9 & $55 \%$ & $45 \%$ \\
\hline
\end{tabular}

Os ensaios laboratoriais foram divididos em três etapas: Etapa 1: Ensaios físico-químicos das amostras antes do processo de biodigestão; Etapa 2: Processo de biodigestão das amostras por meio dos ensaios de determinação do potencial metanogênico bioquímico específico; e Etapa 3: Ensaios físicoquímicos utilizando as amostras digeridas.

Nas análises laboratoriais foram determinados os seguintes parâmetros: Potencial Hidrogeniônico $(\mathrm{pH})$, Sólidos totais (ST), Sólidos Fixos (SF), Sólidos Voláteis (SV), Demanda Química de Oxigênio (DQO), Demanda Bioquímica de Oxigênio (DBO) e Determinação do potencial metanogênico bioquímico específico. Os ensaios físico-químicos seguiram Standard Methods for the Examination of water and Wastewater e os ensaios de determinação do potencial metanogênico bioquímico especifico foram conforme a norma alemã Verein Deutscher Ingenieure - VDI 4630 (2006).

Para a determinação do potencial metanogênico bioquímico foi utilizado inóculo padronizado produzido no laboratório, mantido em temperatura controlada $\left(37^{\circ} \mathrm{C}\right)$ e misturado periodicamente com efluentes de biodigestores para garantir uma elevada atividade microbiana do material. Para a quantificação do biogás produzido em cada amostra, foram utilizados eudiomêtros, ambos compostos por um fermentador 
de $250 \mathrm{~mL}$, um tubo de medição de produção de biogás de $500 \mathrm{~mL}$ e um recipiente para armazenar o líquido de barreira. $\mathrm{O}$ ensaio de determinação de biogás, iniciou-se com o inóculo padrão previamente preparado, e quantificados os sólidos totais e voláteis. Após os preparo das amostras e do inóculo, ambos foram inseridos nos fermentadores e posteriormente incubados em banho maria a uma temperatura em torno de $37+/-2^{\circ} \mathrm{C}$ e conectados da estrutura dos eudiômetros.

Neste processo, o biogás produzido pela digestão anaeróbia nos fermentadores desloca o fluído de barreira no tubo de medição de produção de biogás para o tubo de compensação, de maneira a permitir a leitura da produção de biogás. Para a quantificar a composição de metano $(\mathrm{CH} 4)$ no biogás de cada amostra foi utilizado o medidor portátil de gases da marca Dragger, modelo x-am. 7000. A digestão anaeróbia das amostras ocorreu durante 30 dias, com medições diárias da produção de biogás. A concentração do biogás produzido é apresentada em litros normatizados de gás por kg de sólidos voláteis (LN gás kg SV -1), ou seja, o volume do biogás produzido é calculado em condições normais de 273K e 1013mbar.

\section{RESULTADOS E DISCUSSÃO}

\section{Quantificação de sólidos voláteis e fixos}

O processo de digestão anaeróbia somente degrada a parcela orgânica do efluente, ou seja, os sólidos voláteis (SV). Desta forma, durante o ensaio de produção de biogás os microrganismos presentes convertem os SV em biogás, tendo assim, a redução da concentração dos SV. A figura 1 demostra os teores de SV antes e após a digestão anaeróbia, como também, os sólidos fixos (SF) presentes nas amostras, estes são a fração inorgânica do material, isto é, a parcela que não degrada pelo processo de digestão.

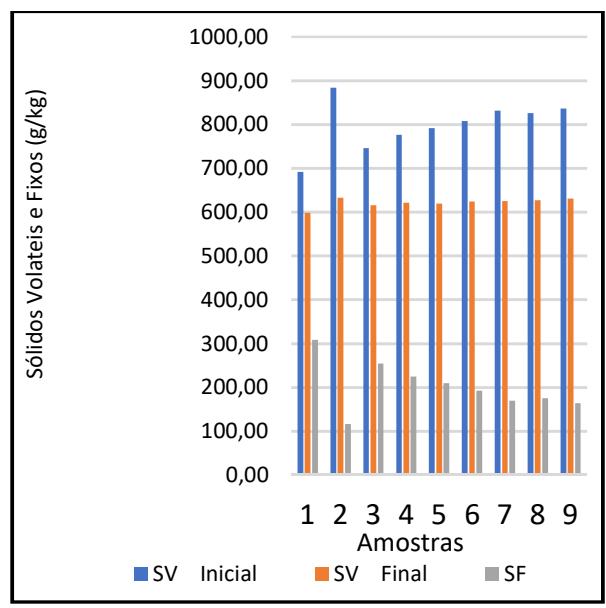

Figura 1: Teores de sólidos voláteis e fixos de cada amostra. Legenda: SV: Sólidos voláteis; SF: Sólidos Fixos.

Nota-se a redução na parcela de SV após o processo de digestão anaeróbia, nas quais os teores de degradação das amostras de co-digestão ocorreram progressivamente de acordo com a quantidade de SV em cada amostra, mostraram-se entre $17,5 \%$ (amostra 3) a $24,6 \%$ (amostra 9). No entanto, as amostras contendo somente dejetos da suinocultura e bovinocultura, apresentaram menor $(13,5 \%)$ e maior $(28,4 \%)$ biodegradação dos SV, respectivamente. Para a amostra de suinocultura o teor de SV inicial foi de 
aproximadamente 70\%. Este valor está próximo ao encontrado por Lucas Júnior (1994), que a partir de dejetos de suinocultura obteve entre 70 e $75 \%$ de SV.

Os SVs são responsáveis diretos pela produção de biogás, isto é, quanto maior o teor de SV, maior o potencial de produção de biogás da biomassa (CHEN, 1983; SANCHEZ et al., 2005). Além dos SV, é importante destacar que, os macronutrientes da biomassa interferem diretamente na produção de biogás e na sua concentração de metano, como proteínas, gorduras e carboidratos (BICHOFSBERGER et al., 2005).

\section{Potencial hidrogeniônico (ph)}

O potencial hidrogeniônico $(\mathrm{pH})$ indica a acidez, neutralidade ou alcalinidade de uma solução aquosa. Este parâmetro pode inibir ou favorecer a produção de biogás, por isso, torna-se fundamental que esteja apropriado para prover um ambiente adequado para os microorganismos durante o processo de digestão anaeróbia. A figura 2 mostra o pH (potencial hidrogeniônico) das amostras antes e após o processo de biodigestão. Verificou-se que os valores médios de pH se apresentaram neutros entre 7,4 a 7,7. Estes valores estão dentro da faixa de 6,0 a 8,0, considerada ideal para a produção de biogás (CHERNICHARO, 1997).

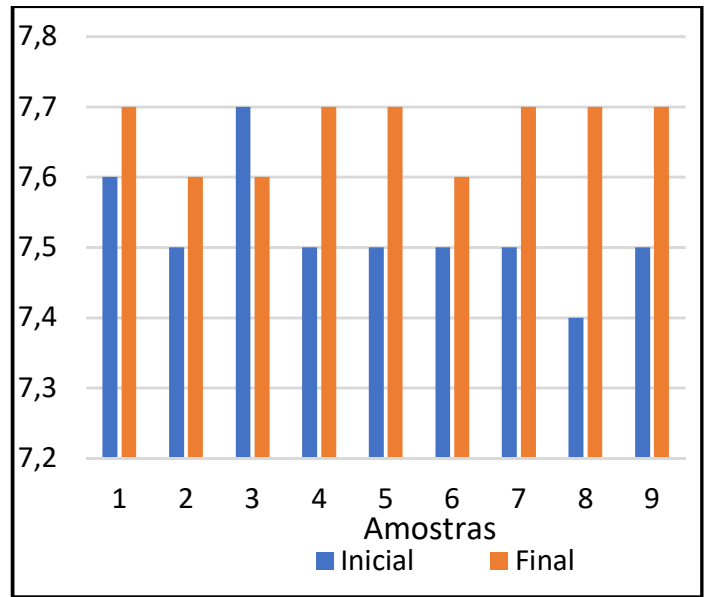

Figura 2: Valores de pH das amostras de biomassa, antes e após a digestão anaeróbia.

\section{Demanda bioquímica de oxigênio e demanda química de oxigênio}

A demanda bioquímica de oxigênio (DBO) e a demanda química de oxigênio (DQO) são parâmetros que determinam a concentração de material orgânico no efluente, ou seja, influenciam na produção de biogás. A DBO é um parâmetro que indica indiretamente a concentração de matéria orgânica biodegradável a partir da demanda de oxigênio consumida por microorganismos. Já a DQO determina a matéria orgânica com base na concentração de oxigênio consumido para oxidar o material orgânico, biodegradável ou não, por ação de um agente químico oxidante forte (MEES, 2006). A Figura 3 a seguir apresenta os resultados da concentração de DBO e DQO de cada amostra, ou seja, a parcela de matéria orgânica das amostras.

Pode-se verificar que as concentrações de DQO são maiores que as de DBO, indo de acordo com Mees (2006), na qual afirma que os índices de DQO são superiores aos de DBO, isto devido as condições da oxidação químicas serem mais expressivas que as oferecidas pelos microorganismos. A menor concentração de DQO e DBO foram obtidas pela amostra composta $100 \%$ de dejetos da suinocultura, $20.150,00 \mathrm{mg} / \mathrm{L}$ e 
$6.972,66 \mathrm{mg} / \mathrm{L}$, respectivamente. A amostra com $100 \%$ de dejetos da bovinocultura, apresentou a maior concentração destes parâmetros, $168.250,00 \mathrm{mg} / \mathrm{L}$ de DQO e $61.170,67 \mathrm{mg} / \mathrm{L}$ de DBO.

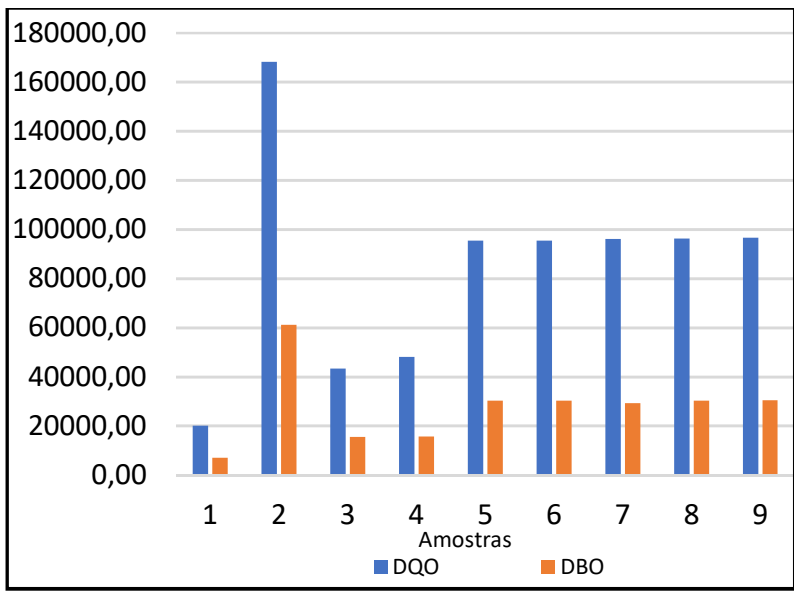

Figura 3: Concentrações de DQO e DBO anterior ao processo de digestão anaeróbia.

Legenda: DBO: Demanda bioquímica de oxigênio; DQO: Demanda química de oxigênio.

Vivan et al. (2010) estudou a biomassa residual da suinocultura e identificaram a concentração de DQO 42000mg/L e DBO 12000mg/L. Novaes et al. (2010) avaliou as características físico-químicas dos dejetos da suinocultura e obteve as concentrações de DQO $13160 \mathrm{mg} / \mathrm{L}$ e DBO $8594 \mathrm{mg} / \mathrm{L}$. Com os dados da literatura e os resultados encontrados neste trabalho, verificou-se que a concentração de DQO e DBO podem variar entre as unidades produtoras de animais. Isto pode decorrer devido a dieta dos animais, modelo do bebedouro e a quantidade de água utilizada na limpeza.

\section{Potencial de produção de biogás}

Por meio do ensaio da determinação do potencial metanogênico bioquímico especifico, foi possível realizar o processo de digestão anaeróbia das biomassas estudas durante 30 dias, a finalização do experimento ocorreu quando as biomassas já digeridas não apresentavam produção de biogás. A figura 4 apresenta a quantidade de biogás e a concentração de metano presente no biogás produzido por cada amostra.

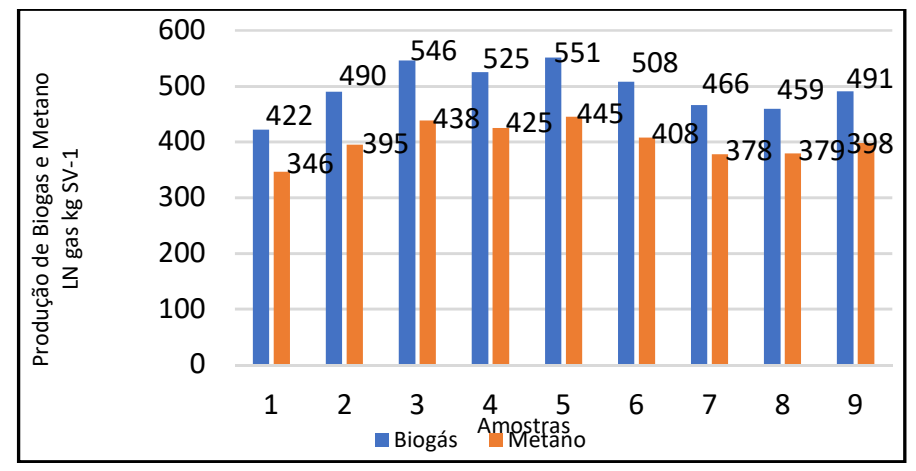

Figura 4: Potencial de produção de biogás e a presença de metano no biogás de cada amostra.

Observa-se que, os dados obtidos neste estudo apontam maior produção de biogás $\left(490 \mathrm{~L}_{N}\right.$ biogás kg $\left.\mathrm{sv}^{-1}\right)$ nos dejetos da bovinocultura em relação aos dejetos de suinocultura ( $422 \mathrm{~L}_{N}$ biogás $\mathrm{kg} \mathrm{sv}^{-1}$ ), apresentando- 
se contraposto com a literatura, a qual indica que os dejetos da suinocultura possuem maior potencial de produção de biogás comparado a bovinocultura.

Orrico Júnior et al. (2011) analisou o potencial de produção de biogás de diferentes resíduos de animais, obtendo resultados dos dejetos da suinocultura 657,18 L biogás kg sv ${ }^{-1}$ e 427,16 L metano kg sv ${ }^{-1} \mathrm{e}$ dos dejetos da bovinocultura 339,09L biogás $\mathrm{kg} \mathrm{sv}^{-1}$ e 237,36L metano $\mathrm{kg} \mathrm{sv}^{-1}$. Moller et al. (2003) obtiveram a produção de metano provenientes de dejetos da suinocultura $356 \mathrm{~L}$ metano.kg sv ${ }^{-1}$ e de dejetos da

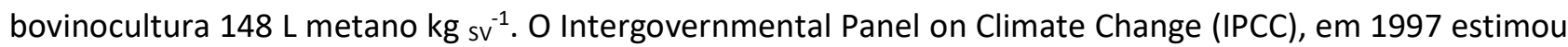
a produção de metano de dejetos da suinocultura e bovinocultura de países desenvolvidos e obteve $450 \mathrm{~L}$ metano $\mathrm{kg} \mathrm{sv}^{-1} \mathrm{e} 240 \mathrm{~L}$ metano $\mathrm{kg} \mathrm{sv}^{-1}$, respectivamente.

A maior produção de biogás pelo substrato proveniente da bovinocultura pode ter ocorrido, devido a alimentação dos bovinos ser realizada apenas por silagem do grão inteiro de milho, este alimento possui menor concentração de lignina em relação ao feno e capim. Segundo Amon et al. (2006), o teor de lignina nos dejetos animais interfere no potencial de produção do biogás e na presença do metano, quanto maior a presença de lignina, maior será a redução deste potencial. Outro fator que pode ter contribuído com este resultado, é a maior concentração de sólidos voláteis, DQO e DBO presente na amostra de dejetos da bovinocultura em relação a suinocultura.

Os resultados demonstram aumento da produção do biogás e maior presença de metano a partir da co-digestão das biomassas residuais da suinocultura e bovinocultura. A amostra 5, composta por $75 \%$ de dejetos de suínos e $25 \%$ de dejetos de bovinos, obteve o maior potencial de produção de biogás e presença de metano, $551 \mathrm{~L}_{N}$ biogás. $\mathrm{kg} \mathrm{sv}^{-1} \mathrm{e} 445 \mathrm{~L}_{N}$ metano.kg sv ${ }^{-1}$.

As amostras de co-digestão 3, 4 e 5 apresentam maiores percentuais de produção do biogás $24 \%$, $19 \%$ e $30 \%$, respectivamente, em relação a amostra 1, composta apenas por dejetos da suinocultura e $11 \%$, $7 \%$ e $12 \%$, na devida ordem, comparada a amostra 2 , constituída somente de dejetos da bovinocultura. As amostras de co-digestão compostas por proporções igual ou superior a 30\% de dejetos da bovinocultura reduziram a produção de biogás, entretanto, mostram-se maiores que os teores da amostra composta somente por dejetos da suinocultura. Portanto, os resultados das análises de produção do biogás a partir da co-digestão dos dejetos da suinocultura e da bovinocultura, apontam o aumento do potencial de produção do biogás a partir da co-digestão destas biomassas, a melhor proporção das biomassas em $75 \%$ de dejetos de suínos e $25 \%$ de dejetos de bovinos.

\section{CONCLUSÕES}

Com base nos resultados obtidos, pode-se concluir que a co-digestão anaeróbia dos dejetos da suinocultura e da bovinocultura potencializa a produção do biogás e a concentração de metano, em relação a digestão isolada destes substratos. A co-digestão da amostra composta por $75 \%$ de dejetos da suinocultura e $25 \%$ da bovinocultura, apresentou o maior potencial de produção do biogás e presença de metano, com $551 \mathrm{~L}_{\mathrm{N}}$ biogás kg sv ${ }^{-1} \mathrm{e} 445 \mathrm{~L}_{\mathrm{N}}$ metano $\mathrm{kg} \mathrm{sv}^{-1}$. A amostra contento somente dejetos da bovinocultura mostraram maior produção de biogás (490L $\mathrm{L}_{N}$ biogás $\mathrm{kg} \mathrm{sv}^{-1}$ ) comparada a amostra composta apenas de dejetos da 
suinocultura (422 $\mathrm{L}_{\mathrm{N}}$ biogás $\left.\mathrm{kg} \mathrm{sv}^{-1}\right)$, estes dados apresentam-se opostos a literatura, a qual aponta a maior produção de biogás para os dejetos da suinocultura.

A partir da análise dos sólidos voláteis, constatou-se a maior concentração de matéria orgânica presente na amostra de dejetos da bovinocultura, afirmando-se que o teor de material orgânico e umidade interferem na quantidade de biogás produzido. Os parâmetros de sólidos voláteis também mostraram a eficiência na remoção da carga orgânica presente nas amostras a partir do processo de digestão anaeróbia, comprovando-se que, este processo é adequado para tratamento de dejetos da bovinocultura e da suinocultura. Desta forma, o tratamento anaeróbio dos dejetos animais, pode contribuir para o saneamento rural, reduzir a contaminação gerada pela concentração de matéria orgânica inserida no solo e na água, como também diminuir o teor de metano lançado na atmosfera entre outros benefícios para o meio ambiente.

\section{REFERÊNCIAS}

AMON, T.; AMON, B.; KRYVORUCHKO, V.; ZOLLITSCH, W.; MAYER, K.; GRUPER, L.. Biogas production from maize and dairy cattle manure: Influence of biomass composition on the methane yield. Agriculture Ecosystems \& Environment, v.118, p.173-182, 2007.

BISCHOFSBERGER, W.; DICHTL, N.; ROSENWINKEL, K. H.; SEYFRIED, C. F.; BÖHNKE, B.. Anaerobtechnik. 2 ed. Berlim: Springer Verlag, 2008.

CHERNICHARO, C. A.. Princípios do tratamento biológico de águas residuárias: reatores anaeróbios. 5 ed. Belo Horizonte: UFMG, 1997

GARFÍ, M.; FERRER-MARTÍ, L.; PEREZ, I.; FLOTATS, X.; FERRER, I.. Codigestion of cow and guinea pig manure in low-cost tubular digesters at high altitude. Ecological engineering, v.37, p.2066-2070, 2011.

GOLDEMBERG, J.; LUCON, O.. Energia e meio ambiente no Brasil. Estudos Avançados, São Paulo, v.21, n.59, p.7-20, 2007.

HUBLIN, A.; ZOKIC, T. I.; ZELIC, B.. Optimization of biogas production from co-digestion of whey and cow manure. Biotechnology and Bioprocess Engineering, v.17, p.12841293, 2012.

KONRAD, O.; MACHADO, C. A.; BRIETZKE, D. T.; SECCHI, F. J.; NICHEL, L.; MARDER, M.. Avaliação da utilização de dejeto bovino com e sem uso de glicerina em biodigestores operados em batelada. Destaques acadêmicos, Lajeado, v.4, n.4, 2012.
KONRAD, O.; SCHMEIER, N. P.; ANATER, A. T.; CASARIL, C.; LUMI, M.. Geração de biogás através de digestão anaeróbia utilizando substrato suíno e bovino. Ciências Agrárias e Ambientais, Curitiba, v.12, n.3, p.209-214, 2014.

MACEDO, J. A. B.. Águas e Águas. São Paulo: Varela, 2001.

MARCO, A. P.; ORRICO JÚNIOR; ORRICO, A. C.; LUCAS JUNIOR, J.. Produção animal e o meio ambiente: uma comparação entre potencial de emissão de metano dos dejetos e a quantidade de alimento produzido. Engenharia Agrícola, Jaboticabal, v.31, n.2, p.399-410, 2011.

MEES, J. B. R.. Tratamento de Águas Residuárias. Medianeira: Universidade Tecnológica Federal do Paraná, 2006.

MOLLER, H. B.; SOMMER, S. G.; AHRING, B. K.. Methane productivity of manure, straw and solid fractions of manure. Biomass \& Bioenergy, v.26, p.485-495, 2004.

SANCHEZ, E.; BORJA, R.; TRAVIESO, L.; MARTIN, A.; COLMENAREJO, M. F.. Effect of organic loading rate on the stability, operational parameters and performance of a secondary upflow anaerobic sludge bed reactor treating piggery waste. Bioresource technology, v.96, n.3, 2005.

VIVAN, M.; KUNZ, A.; STOLBERG, J.; PERDOMO, C.; TECHIO, V. H.. Eficiência da interação biodigestor e lagoas de estabilização na remoção de poluentes em dejetos de suínos. Revista Brasileira de Engenharia Agrícola e Ambiental, Campina Grande, v.14, n.3, p.320-325, 2010. 